\title{
Primary Leiomyosarcoma of the Mesentery: A Case Report With Review of Literature
}

\author{
Saif Affas ${ }^{1}$, Mohamad F. Ayas ${ }^{1}$, Juliann M. Mendes ${ }^{2}$, Tarik Hadid $^{3}$ \\ 1. Internal Medicine, Ascension St. John Hospital and Medical Center, Detroit, USA 2. Pathology and Laboratory \\ Medicine, Ascension St. John Hospital and Medical Center, Detroit, USA 3. Oncology, Ascension St. John Hospital and \\ Medical Center, Detroit, USA
}

Corresponding author: Saif Affas, saif.affas@gmail.com

\begin{abstract}
Mesenteric leiomyosarcoma (LMS) is a rare gastrointestinal mesenchymal tumor. It was often misdiagnosed as a gastrointestinal stromal tumor (GIST) until the introduction of immunohistochemistry staining (IHC) in 1998. Currently, a positive IHC staining for smooth muscle markers represents the main diagnostic modality. Herein, we present a case of Mesenteric LMS in a 68-year-old woman, who presented with nausea, vomiting, and abdominal pain and was found to have a right-sided mesenteric tumor encasing the right ureter, with right hydroureteronephrosis. The patient underwent surgical removal of the tumor and IHC stains were compatible with LMS. She achieved remission until she developed recurrence 12 months after initial diagnosis and subsequently expired due to postoperative complications when re-resection was attempted. Typically, mesenteric LMS carries a poor prognosis with a propensity for hematogenous metastasis. In the absence of a standardized protocol for therapy, early surgical resection is the only known curative modality but with a high risk of recurrence.
\end{abstract}

Review began 09/21/2020 Review ended 10/01/2020 Published 10/03/2020

\section{() Copyright 2020}

Affas et al. This is an open access article distributed under the terms of the Creative Commons Attribution License CC-BY 4.0., which permits unrestricted use, distribution, and reproduction in any medium, provided the original author and source are credited.
Categories: Pathology, Gastroenterology, Oncology

Keywords: primary leiomyosarcoma, leiomyosarcoma, mesentery, gist, literature review of disease

\section{Introduction And Background}

Leiomyosarcoma (LMS) is a rare malignant soft tissue tumor that originates from smooth muscle cells, with an incidence rate of 1 per 350,000 cases [1,2]. Although mainly found in the retroperitoneum, uterus, and medium to large abdominal vessels, it can rarely arise from the mesenteric smooth muscles [3,4]. Prior to the development of immunohistochemical (IHC) staining, LMS was frequently misdiagnosed as a gastrointestinal stromal tumor (GIST), given the histological similarities as both entities are under the umbrella of gastrointestinal mesenchymal tumors. IHC is currently considered essential for the accurate diagnosis of LMS $[1,5,6]$. Similar to most soft tissue sarcomas, LMS tends to grow along the tissue planes and thus can compress surrounding structures, leading to the formation of a pseudo-capsule with fingerlike projections that can infiltrate adjacent tissues [7].

\section{Case report}

A 68-year-old woman with a history of type 2 diabetes mellitus, essential hypertension, and latent tuberculosis presented to the hospital with generalized fatigue, weakness, and unintentional 10-pound weight loss over two months. She also reported abdominal pain, nausea, vomiting, and diarrhea for two days but denied fever, chills, and night sweats. At presentation, vital signs were normal. Her examination showed a soft, nondistended abdomen with mild right upper quadrant tenderness on palpation, but without hepatosplenomegaly, and with a negative Murphy's sign.

Laboratory studies showed a hemoglobin of $9.9 \mathrm{gm} / \mathrm{dl}$, and a white blood cell of $9.7 \mathrm{Thou} / \mathrm{cu} \mathrm{mm}$. Blood smear showed normochromic normocytic anemia with mild anisocytosis. The iron panel was normal apart from mildly elevated serum ferritin with a normal vitamin B12 and RBC folate level. The patient had a colonoscopy done one month before her presentation in another facility which was reportedly negative.

An enhanced computed tomography (CT) of the chest, abdomen, and pelvis revealed a $5.7 \times 4.2 \times 5.7 \mathrm{~cm}^{3}$ right-sided mesenteric mass causing extrinsic compression of the right mid-ureter with prominent rightsided hydroureteronephrosis (Figure 1). No pulmonary, hepatic lesions, or lymphadenopathy were identified. 


\section{Cureus}
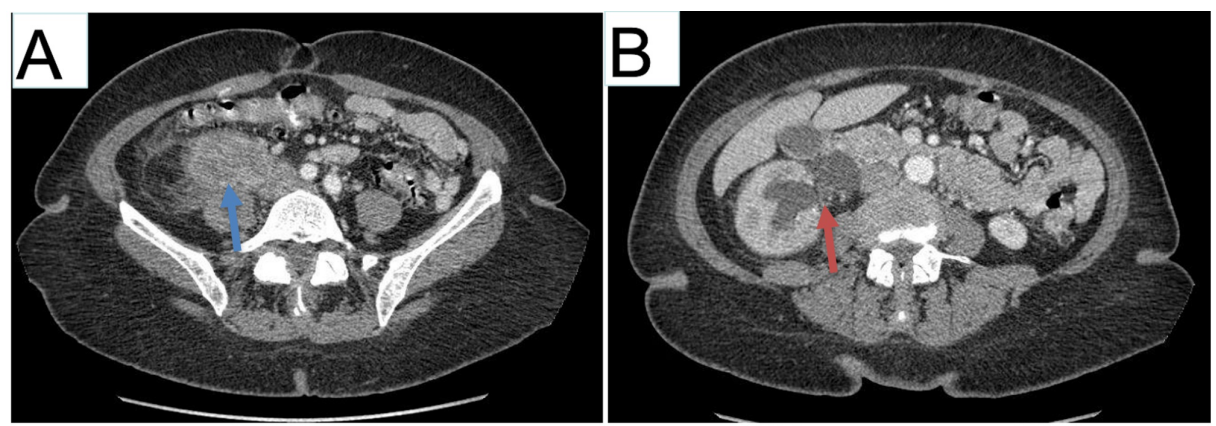

\section{FIGURE 1: CT findings}

(A) Solid and cystic mass in the right retroperitoneum, measured $5.7 \times 4.2 \times 5.7 \mathrm{~cm}^{3}$ in size (blue arrow). (B) Right hydronephrosis and proximal and mid-right hydroureter (red arrow) due to external compression effect of the mass.

A CT-guided biopsy of the mass was performed and was suspicious for smooth muscle neoplasm. After insertion of a right-sided ureteral stent and improvement of the patient's symptoms, she underwent an exploratory laparotomy, which revealed a mass encasing the right mid-ureter, which was resected and underwent subsequent ureteroureterostomy. A complete surgical excision was performed as per operative report; however, tumor cells were present at the inked resection margin, hence, it was classified as an intralesional excision. Pathologic examination also demonstrated neoplastic cells with atypical elongated nuclei with abundant pleomorphism, heterogeneous chromatin, and atypical mitoses. The tumor was graded according to the French Federation of Cancer Centers Sarcoma Group (FNCLCC) on the basis of tumor differentiation (score 1) [8]. Furthermore, the mitotic rate was 26 per 10 high power field (score 3), and necrosis was up to 30\% (score 1). This gives an overall score of 5-6 and a grade of 2 (Figure 2).

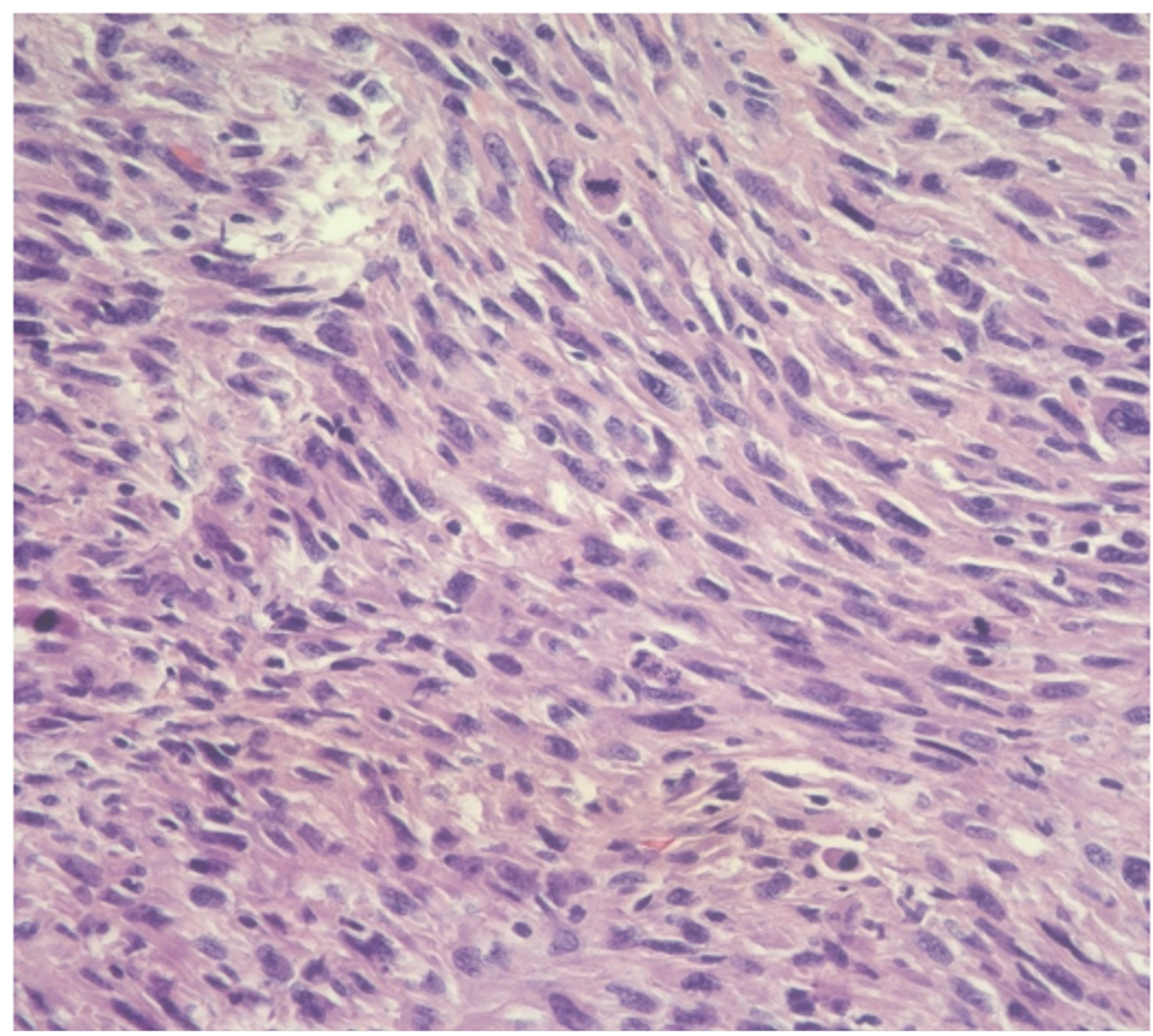

\section{FIGURE 2: Histopathology}

Masson's trichrome stain showing neoplastic cells in whorls with pleomorphism and high mitotic activity. 
and focally positive for desmin and caldesmon (Figure 3); however, the neuronal marker S100 and the interstitial markers CD117 and CD34 were negative. Ki-67 index was very high at 90\%, suggestive of high mitotic activity. This histopathological picture is most compatible with mesenteric LMS.
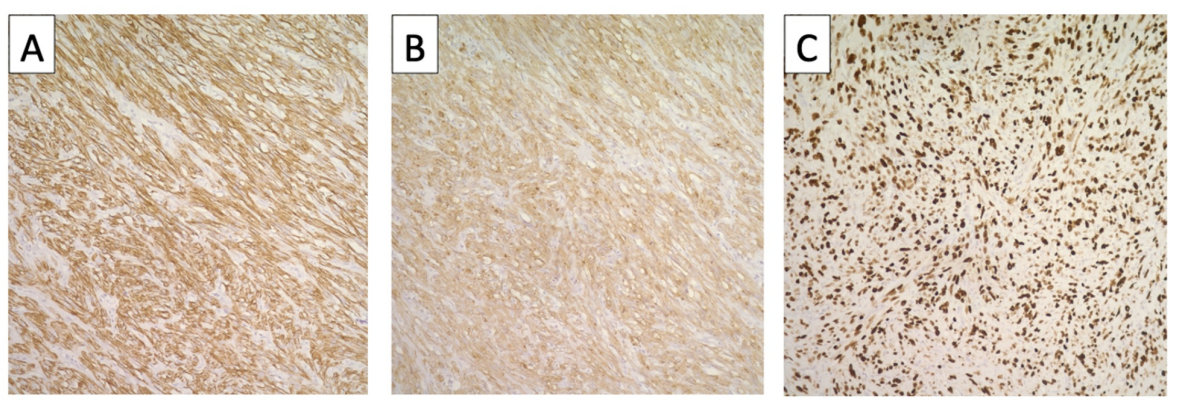

\section{FIGURE 3: Immunohistochemistry stains}

(A) Actin stain in yellow brown, (B) smooth muscle actin in yellow, and (C) Ki69 stain in dark showing high mitotic activity nuclei.

The patient remained disease-free for one year, until she presented with recurrent nausea, vomiting, diarrhea, and diffuse abdominal pain. A repeat CT scan of the abdomen and pelvis was worrisome for tumor recurrence, as it revealed a $2.0 \times 1.8 \times 2.7 \mathrm{~cm}^{3}$ enhancing mass compressing the right ureter and causing hydronephrosis. Exploratory laparotomy was performed, and a $3 \mathrm{~cm}$ retroperitoneal right lower quadrant mass was found and appeared to be arising from the ascending mesocolon with right ureter obstruction. She underwent right hemicolectomy and right nephrectomy and pathology confirmed recurrence. Unfortunately, the patient developed postoperative complications resulting in her death six days postoperatively.

\section{Review}

Mesenteric LMS was first described in 1963 by Kato et al. and is derived from the smooth muscle of mesenteric blood vessels [5], which may explain the frequent hematogenous metastasis. Mesenteric LMS most commonly involves the meso-ileum, but there are rare reported cases involving the transverse, ascending, descending, and sigmoid mesocolon as well as the omentum and gastro-hepatic ligament [1,5,911]. While the presentation of LMS is often vague and variable, it most commonly presents with obstructive symptoms such as nausea, vomiting, diarrhea, abdominal distention, and nonspecific abdominal pain. Many patients also have palpable abdominal masses and unintentional weight loss $[3,4,9]$. Approximately $50 \%$ of patients will develop distant metastasis, most commonly to the liver, and lungs $[3,9,11]$, and rarely to adjacent lymph nodes [7]; therefore, routine lymph node dissection is not recommended.

The prognosis of LMS is quite poor as the overall five-year survival rate is at $20 \%$ to $30 \%$, which is thought to be due to the large available space in the abdominal cavity, rendering the tumor undetectable until late in the disease course $[3,4,9]$.

In our current literature review, we performed a PubMed database search using the keyword "mesenteric leiomyosarcoma" and since IHC was introduced in 1998 as an essential element to differentiate between GIST and LMS [5,12-15], any reported cases prior to 1998, were excluded for the current study. The largest case review of mesenteric LMS was reported by Kato et al. and included 13 patients between the years 1999 and 2016 [5]. In our search, we included new cases from 2016 to 2020, and a total of 20 articles were initially identified. After reviewing these articles, 14 articles were excluded from this literature review as they either did not originate from the mesentery [13] or were not in English [1], therefore, a total of six new cases of mesenteric LMS, including our case were compiled.

\section{Literature review results}

Data were analyzed after all 19 eligible cases were compiled. The median age of presentation for patients with mesenteric LMS was 55 years (range: 13-86), and 68\% $(n=13)$ were females. When mentioned, patients most commonly reported abdominal pain or palpable abdominal mass. Interestingly, one rare case presented with posterior reversible encephalopathy syndrome (PRES) [3]. The most commonly encountered location is the small intestine mesentery (seven cases), followed by the meso-sigmoid (five cases), ascending mesocolon (two cases), descending mesocolon (one case), mesorectum (one case), and 16\% (three cases) only stated location as "mesenteric," without specification (Table 1). 


\section{Cureus}

\begin{tabular}{|c|c|c|c|c|c|c|c|c|c|}
\hline Age/gender & Presentation & $\begin{array}{l}\text { Size } \\
(\mathrm{mm})\end{array}$ & Chemotherapy & Metastasis & $\begin{array}{l}\text { Interval between initial } \\
\text { diagnosis and metastasis } \\
\text { (months) }\end{array}$ & $\begin{array}{l}\text { Recurrence } \\
\text { of primary }\end{array}$ & $\begin{array}{l}\text { Interval between initial } \\
\text { diagnosis and recurrence } \\
\text { (months) }\end{array}$ & $\begin{array}{l}\text { Documented } \\
\text { follow-up } \\
\text { (months) }\end{array}$ & $\begin{array}{l}\text { Reference } \\
\#\end{array}$ \\
\hline $50 \mathrm{~F}$ & $\begin{array}{l}\text { Mass, change in } \\
\text { bowel habits }\end{array}$ & 140 & NR & None & NR & No & NR & 6 & [1] \\
\hline $82 \mathrm{~F}$ & Mass, pain & 110 & No & Liver & 24 & No & NR & 24 & [2] \\
\hline $52 \mathrm{~F}$ & Pain, PRES & 100 & Yes & Liver, lung & 0 & Yes & 5 & 20 & [3] \\
\hline $62 \mathrm{~F}$ & Mass & 140 & Yes & Liver & 0 & NR & NR & 10 & [4] \\
\hline $76 \mathrm{~F}$ & Mass & 140 & No & Liver & 24 & No & NR & 40 & [5] \\
\hline $45 \mathrm{~F}$ & Mass & 140 & NR & None & NR & No & NR & 9 & [6] \\
\hline $40 \mathrm{~F}$ & Pain, distension & 80 & Yes & Liver, lung & 3 & No & NR & 39 & [9] \\
\hline $65 \mathrm{M}$ & Mass, pain & 200 & Yes & Liver, local & 11 & Yes & 3 & 30 & [10] \\
\hline $49 \mathrm{~F}$ & NR & NR & NR & Liver & 29 & $\mathrm{NR}$ & NR & 59 & [11] \\
\hline $46 \mathrm{M}$ & NR & NR & NR & Liver, lung & 16 & NR & NR & 26 & [11] \\
\hline $41 \mathrm{M}$ & NR & 230 & $\mathrm{NR}$ & Liver & 0 & NR & NR & 15 & [12] \\
\hline $86 \mathrm{M}$ & NR & 125 & NR & None & NR & NR & NR & 3 & [12] \\
\hline $46 \mathrm{~F}$ & Mass & NR & Yes & Liver, local & 48 & Yes & 6 & 58 & [13] \\
\hline $62 \mathrm{~F}$ & N.M & 78 & Yes & Liver, local & 0 & $\mathrm{NR}$ & NR & 24 & [13] \\
\hline $62 \mathrm{~F}$ & Pain & 210 & Yes & Omentum & 0 & $\mathrm{NR}$ & NR & NR & [14] \\
\hline $13 \mathrm{M}$ & Mass & 100 & NR & None & NR & NR & NR & 3 & [16] \\
\hline $33 \mathrm{M}$ & Pain & 150 & NR & None & NR & NR & NR & $\mathrm{NR}$ & {$[17]$} \\
\hline $62 \mathrm{~F}$ & Fullness & 220 & NR & None & NR & No & NR & 6 & [18] \\
\hline $68 \mathrm{~F}$ & Pain, vomiting & 57 & No & None & NR & Yes & 12 & 12 & NR \\
\hline
\end{tabular}

\section{TABLE 1: Demography and treatment}

Summary for previously published case report demographic and management.

PRES: posterior reversible encephalopathy syndrome, M: male, F: female, NR: not reported.

Although the size of the tumor was not always reported, the largest reported tumor was $230 \mathrm{~mm}$ [12], with a median size of $139 \mathrm{~mm}$ (range: $57-230 \mathrm{~mm}$ ). Out of the total cases reported, $42 \%(\mathrm{n}=8)$ had liver metastasis, $16 \%(n=3)$ had synchronous liver and lung metastasis, 37\% $(n=7)$ had no metastasis, and $5 \%(n=1)$ had metastasis to the omentum. Of those mentioned, five cases had metastasis seen on the initial diagnosis of the primary tumor. The median interval between initial diagnosis and development of metastasis when reported was 13 months (range: $0-48$ ) and 21\% (4 cases) showed recurrence of the primary tumor within a median of 6.5 months of initial diagnosis (range: 3-12 months).

Given that LMSs originate from smooth muscle cells, confirming the diagnosis with IHC is necessary for accurate diagnosis [5]. SMA $(n=17)$ was positive in $100 \%$ of the reported cases. When tested, actin $(n=3)$, caldesmon $(n=4)$, and vimentin $(n=5)$ were all positive. Of those that tested for desmin $(n=17)$, all except one case were positive. Of the cases that tested for S100 $(n=10)$ and CD $117(\mathrm{c}-\mathrm{KIT})(\mathrm{n}=14)$, all were negative. As for CD34 ( $\mathrm{n}=10)$, all were negative except one that was minimally positive (Table 2 ). 


\begin{tabular}{|c|c|c|c|c|c|c|c|c|}
\hline References & Actin & SMA & Caldesmon & Vimentin & Desmin & S100 & CD34 & CD117 \\
\hline Miettinen et al. [12] & $n / a$ & + & $n / a$ & $n / a$ & + & - & - & - \\
\hline Miettinen et al. [12] & $\mathrm{n} / \mathrm{a}$ & + & $\mathrm{n} / \mathrm{a}$ & $\mathrm{n} / \mathrm{a}$ & + & - & - & - \\
\hline Fukanaga [4] & + & + & $\mathrm{n} / \mathrm{a}$ & + & + & - & - & - \\
\hline Simonovich et al. [2] & + & $n / a$ & $\mathrm{n} / \mathrm{a}$ & + & + & $\mathrm{n} / \mathrm{a}$ & - & - \\
\hline lwasaki et al. [16] & $\mathrm{n} / \mathrm{a}$ & $\mathrm{n} / \mathrm{a}$ & $\mathrm{n} / \mathrm{a}$ & + & - & - & - & $\mathrm{n} / \mathrm{a}$ \\
\hline Koczkowska et al. [13] & $\mathrm{n} / \mathrm{a}$ & + & $\mathrm{n} / \mathrm{a}$ & $\mathrm{n} / \mathrm{a}$ & + & - & - & - \\
\hline Koczkowska et al. [13] & $\mathrm{n} / \mathrm{a}$ & + & $\mathrm{n} / \mathrm{a}$ & $\mathrm{n} / \mathrm{a}$ & + & $\mathrm{n} / \mathrm{a}$ & - & - \\
\hline Mizobe et al. [10] & $\mathrm{n} / \mathrm{a}$ & + & $\mathrm{n} / \mathrm{a}$ & $\mathrm{n} / \mathrm{a}$ & $\mathrm{n} / \mathrm{a}$ & - & $\mathrm{n} / \mathrm{a}$ & - \\
\hline Sidhic et al. [17] & $\mathrm{n} / \mathrm{a}$ & + & $\mathrm{n} / \mathrm{a}$ & $\mathrm{n} / \mathrm{a}$ & $\mathrm{n} / \mathrm{a}$ & $\mathrm{n} / \mathrm{a}$ & - & - \\
\hline Hamed et al. [11] & $\mathrm{n} / \mathrm{a}$ & + & $\mathrm{n} / \mathrm{a}$ & $\mathrm{n} / \mathrm{a}$ & + & $\mathrm{n} / \mathrm{a}$ & $\mathrm{n} / \mathrm{a}$ & - \\
\hline Hamed et al. [11] & $n / a$ & + & $n / a$ & $n / a$ & + & $n / a$ & $n / a$ & - \\
\hline Dasgupta et al. [18] & $\mathrm{n} / \mathrm{a}$ & + & $n / a$ & $n / a$ & + & $n / a$ & $n / a$ & - \\
\hline Kato et al. [5] & $\mathrm{n} / \mathrm{a}$ & + & $\mathrm{n} / \mathrm{a}$ & $\mathrm{n} / \mathrm{a}$ & + & - & $\mathrm{n} / \mathrm{a}$ & - \\
\hline Varghese et al. [9] & $n / a$ & + & + & $n / a$ & + & $n / a$ & $n / a$ & $n / a$ \\
\hline llias et al. [6] & $\mathrm{n} / \mathrm{a}$ & + & + & $n / a$ & + & - & + & - \\
\hline Dalal et al. [1] & $\mathrm{n} / \mathrm{a}$ & + & $\mathrm{n} / \mathrm{a}$ & + & + & - & - & - \\
\hline Schoucair et al. [3] & $n / a$ & + & + & $n / a$ & + & $\mathrm{n} / \mathrm{a}$ & $\mathrm{n} / \mathrm{a}$ & $\mathrm{n} / \mathrm{a}$ \\
\hline Yoon et al. [14] & $\mathrm{n} / \mathrm{a}$ & + & $\mathrm{n} / \mathrm{a}$ & $\mathrm{n} / \mathrm{a}$ & + & $\mathrm{n} / \mathrm{a}$ & $\mathrm{n} / \mathrm{a}$ & $\mathrm{n} / \mathrm{a}$ \\
\hline Our reported case & + & + & + & + & + & - & $n / a$ & $n / a$ \\
\hline
\end{tabular}

\section{TABLE 2: IHC review}

All reviewed LMS cases and IHC stain report.

LMS: leiomyosarcoma, IHC: immunohistochemistry, n/a: no answer, MAL: smooth muscle actin, +: positive, -: negative.

All patients were managed with surgical resection, apart from two cases where modality of treatment was not reported. The extent of resection was dependent on whether there is an invasion of adjacent structures. Only $37 \%$ (7 cases) underwent chemotherapy and of those, six cases underwent palliative/salvage chemotherapy $[3,4,9,10,13]$, and a patient had adjuvant chemotherapy [14]. Of those who underwent salvage chemotherapy, two discontinued therapy due to side effects and subsequently died due to disease progression [13], three patients developed new liver metastasis after chemotherapy [3,4,10], and only one patient showed a response with a decrease in tumor size and subsequently underwent radioablation of the lung and liver masses with a 36-month tumor-free follow up [9]. The response of the patient who underwent adjuvant therapy was not reported [14]. Two out of the seven patients who received salvage chemotherapy did not respond to chemotherapy and subsequently underwent chemoembolization of metastatic lesions $[10,13]$. These clinical reports put into question the efficacy of chemotherapy in mesenteric LMS but suggest a clinical benefit of chemoembolization. However, this is yet to be established in clinical trials.

Postoperative serial imaging such as a CT chest, abdomen, and pelvis is recommended in LMS. As noticeable in our review, $63 \%(n=12)$ of patients had positive metastasis in a median of 13 -months and $21 \%(n=4)$ showed recurrence of primary tumor within a median of 6.5 months (Table 1). Therefore, in patients who underwent complete tumor resection, strategic surveillance is recommended every three to six months for two to three years, and then annually [7]. Recommendations in those with positive margins include a physical examination with abdominal and pelvic imaging every three to six months for two to three years, then six months for the next two years, and then annually. Moreover, due to the high rate of lung metastasis, CT of the chest is also indicated annually. 
The median follow-up time for the cases presented ( $n=17$ ) was 22.6 months (range: $3-59)$, and consistent with the findings of Kato et al. [5], no patient was reported to survive 59 months (Table 1) [11].

\section{Conclusions}

Mesenteric LMS are rare tumors, with aggressive behavior as manifested by their high metastatic rate. The clinical course appears to be variable based on location and histologic characteristics. Differentiating LMS from GISTs histologically can be challenging, given the diversity in morphology. Perhaps, the best way of separating the two entities is by IHC. As LMS are derived from smooth muscle cells, they stain positively for smooth muscle markers and negatively for intestinal markers. Conversely, GISTs arise from the interstitial cells of Cajal and stain positively with C-kit, DOG1, and CD34.

In this report, we review the common clinical and diagnostic characteristics of mesenteric LMS and highlight the limitation of our knowledge in this rare entity. Therefore, further research is needed to optimize management and improve the prognosis of LMS.

\section{Additional Information}

\section{Disclosures}

Conflicts of interest: In compliance with the ICMJE uniform disclosure form, all authors declare the following: Payment/services info: All authors have declared that no financial support was received from any organization for the submitted work. Financial relationships: All authors have declared that they have no financial relationships at present or within the previous three years with any organizations that might have an interest in the submitted work. Other relationships: All authors have declared that there are no other relationships or activities that could appear to have influenced the submitted work.

\section{References}

1. Dalal V, Kaur M, Menia R, Siraj F, Bhatnagar A, Agrawal U: Primary leiomyosarcoma of the mesentery: a case report. Iran J Med Sci. 2017, 42:505-508

2. Simonovich CJ, Hardman JM, Navin JJ, Jacobs J, Fergusson N: An unusual abdominal tumor leiomyosarcoma of the mesentery: a case report. Hawaii Med J. 2006, 65:18-20.

3. Schoucair R, Nicolas G, Ahdab R, Bejjani N, Abdalla EK: Posterior reversible encephalopathy syndrome (PRES) in mesenteric leiomyosarcoma: a case report. Int J Surg Case Rep. 2018, 49:96-101. 10.1016/i.ijscr.2018.04.043

4. Fukunaga M: Neuron-specific enolase-producing leiomyosarcoma of the mesentery. APMIS. 2004, 112:105108. 10.1111/j.1600-0463.2004.apm1120204.x

5. Kato T, Noda H, Abe I, Alonso S, Yokoyama N, Rikiyama T: Curative resection for leiomyosarcoma of the descending mesocolon with metachronous liver metastasis: a case report and literature review. Mol Clin Oncol. 2016, 5:53-56. 10.3892/mco.2016.874

6. Ilias AS, Yaacob H, Wan Zain WZ, Zakaria AD: Rare case of primary leiomyosarcoma of sigmoid mesocolon . BMJ Case Rep. 2017, 2017:bcr2017219826. 10.1136/bcr-2017-219826

7. Fong Y, Coit DG, Woodruff JM, Brennan MF: Lymph node metastasis from soft tissue sarcoma in adults: analysis of data from a prospective database of 1772 sarcoma patients. Ann Surg. 1993, 217:72-77. 10.1097/00000658-199301000-00012

8. Khoury JD, Coffin CM, Spunt SL, Parham DM: Grading of nonrhabdomyosarcoma soft tissue sarcoma in children and adolescents: a comparison of parameters used for the Fédération Nationale des Centers de Lutte Contre le Cancer and Pediatric Oncology Group Systems. Cancer. 2010, 116:2266-2274. 10.1002/cncr.24929

9. Varghese M, Bruland O, Wiedswang AM, Lobmaier I, Røsok B, Benjamin RS, Hall KS: Metastatic mesenteric dedifferentiated leiomyosarcoma: a case report and a review of literature. Clin Sarcoma Res. 2016, 6:2. 10.1186/s13569-016-0042-6

10. Mizobe T, Akagi Y, Ishikawa H, et al.: Gemcitabine with paclitaxel therapy against mesocolic leiomyosarcoma: a case report. Anticancer Res. 2013, 33:2929-2933.

11. Hamed MO, Roberts KJ, Merchant W, Lodge JP: Contemporary management and classification of hepatic leiomyosarcoma. HPB (Oxford). 2015, 17:362-367. 10.1111/hpb.12366

12. Miettinen M, Monihan JM, Sarlomo-Rikala M, Kovatich AJ, Carr NJ, Emory TS, Sobin LH: Gastrointestinal stromal tumors/smooth muscle tumors (GISTs) primary in the omentum and mesentery: clinicopathologic and immunohistochemical study of 26 cases. Am J Surg Pathol. 1999, 23:1109-1118. 10.1097/00000478199909000-00015

13. Koczkowska M, Lipska BS, Grzeszewska J, Limon J, Biernat W, Jassem J: Primary leiomyosarcoma of the mesentery in two sisters: clinical and molecular characteristics. Pol J Pathol. 2013, 64:59-63. 10.5114/pjp.2013.34605

14. Yoon HJ, Hyun DW, Hwang SY, et al.: An unusual case of dedifferentiated leiomyosarcoma of the primary mesentery mimicking ovarian cancer. Int J Clin Exp Pathol. 2019, 12:4150-4155.

15. Hirota S, Isozaki K, Moriyama Y, et al.: Gain-of-function mutations of c-kit in human gastrointestinal stromal tumors. Science. 1998, 279:577-580. 10.1126/science.279.5350.577

16. Iwasaki M, Kitaguchi K, Kobayashi H: Mesenteric leiomyosarcoma in a 13-year-old boy. J Pediatr Surg. 2010, 45:1893-1895. 10.1016/j.jpedsurg.2010.05.015

17. Sidhic AK, Ranjith M, Ali KP, Tej PR: Leiomyosarcoma of the mesentry, a rare mesentric tumour . Int J Surg Case Rep. 2015, 7:58-60. 10.1016/j.ijscr.2014.11.082

18. Dasgupta S, Chakrabarti S, Ghosh S, Das S: Ileal mesenteric leiomyosarcoma: report of a rare neoplasm . J 


\section{Cureus}

Gastrointest Cancer. 2016, 47:114-117. 10.1007/s12029-015-9725-0 